\title{
Economic assessment of PSS value networks - an algorithmic appraoch
}

\author{
Khaled Medini ${ }^{1}$, Xavier Boucher ${ }^{1}$, Sophie Peillon $^{2}$, Hervé Vaillant $^{3}$ \\ ${ }^{1}$ Mines Saint-Etienne, Univ Clermont Auvergne, CNRS, UMR 6158 LIMOS, Institut Henri \\ Fayol, F - 42023, Saint-Etienne France \\ ${ }^{2}$ Mines Saint-Etienne, Univ Lyon, COACTIS EA4161, Institut Henri Fayol, F - 42023 Saint- \\ Etienne France \\ ${ }^{3}$ Mines Saint-Etienne, Univ Lyon, CNRS, UMR 5600 EVS, Institut Henri Fayol, F - 42023 \\ Saint-Etienne France \\ $\{$ khaled.medini, boucher, peillon, vaillant\}@emse.fr
}

\begin{abstract}
Product-Service Systems (PSS) are one of the business innovation drivers in terms of increasing the value for the customer and for the actors involved in PSS provision. This paper reports on a framework for assessing the economic value out of PSS provision considering a multi-actor perspective. The originality of the proposed framework is twofold: enabling an attribution of the costs (and revenues) to the actors involved in the value network, and considering the peculiarities of the use phase in cost and revenue calculation, i.e. impact of PSS contract duration and of the intensification of the product use through take-back systems.
\end{abstract}

Keywords: Customer-centric, Actors, Economic Assessment, Algorithmic.

\section{Introduction}

Manufacturing industry is increasingly shaped by fierce competition and demanding customers. Subsequently, the focus on an attractive offering and on customer loyalty took the lead over traditional price war. Product-Service Systems (PSS) are one of the innovation drivers of the business in terms of increasing the value for the customer and for the actors involved in PSS provision (Baines et al., 2007; Meier et al., 2010; Beuren et al., 2013). A PSS can be seen as "a system of products, services, networks of players and supporting infrastructure that continuously strives to be competitive, satisfy customer..." (Goedkoop et al., 1999). The inherent PSS complexity requires a close collaboration among its stakeholders. This allows for properly defining the value transfer scheme(s) throughout the PSS provider network and with regard to the final customer (Beuren et al., 2013; Brehmer et al., 2018). Within such a process, each actor needs to have a deep understanding of the value proposition (Baldassarre et al., 2017). Consequently, PSS actors require an overview of the subsequent PSS potential benefits and risks, particularly in terms of costs and expected revenues for each of the value network actors (Datta and Roy, 2010; Estrada et al., 2017). This 
means that an assessment is needed to be conducted in parallel with the iterative process of defining value proposition scenarios (Medini et al., 2014; Baldassarre et al., 2017).

This paper reports on a framework for PSS economic value assessment considering a multi-actor perspective. The originality of the proposed framework lies in enabling an attribution of the costs (and revenues) to the actors involved in the value network, and considering the peculiarities of the use phase in PSS economic assessment, i.e. impact of PSS contract duration and of the intensification of the product use through take-back systems. The remainder of the paper is organised as follows: Section 2 provides somes insights into the literature related to PSS value network dimension and economic assessment. Section 3 reports on a framework for PSS economic assessment. Section 4 reports on an illustrative example. A brief conclusion is presented in Section 5.

\section{Multi-actor economic assessment of PSSs}

While PSS offers are likely to maximize the value for both customer and provider, they usually involve several actors, each supporting one or more phases of the product and/or service life cycle (Meier et al., 2010; Cavalieri and Pezzotta, 2012). Thus, the value creation goes beyond a single company perspective and relies on a co-creation process involving different stakeholders to meet customers' demands while ensuring satisfactory value for each of the stakeholders (Ramaswamy and Ozcan, 2014; Baldassarre et al., 2017; Smith and Wuest, 2017). Authors such as Medini et al. (2014) approached the various value transfer alternative schemes through the notion of scenario. A scenario refers to an assignment of a set of activities to a set of actors to deliver a given PSS. The scenarios are defined by the PSS actors based on a set of guidelines easing the generation and filtering of the ideas (Andriankaja et al., 2018). Complementarily, Lindhal et al. (2017) use actors' maps to visually represent PSS actors and their interrelationships. Basically, an actors' map uses input from the stakeholders collected during workshops. Further research works about value capture and representation in multi-stakeholders perspective can be found in (Brehmer et al., 2018). Basically, these works contribute towards the definition of a common understanding of how the value will be created and captured by each of the actors. However a comprehensive value assessment requires a multiperspective analysis of the value proposition for each of the actors, and even iteratively testing the predefined scenarios (Medini and Boucher, 2016; Baldassarre et al., 2017).

From an economic perspective, the assessment of the value in PSSs (particularly use oriented and result oriented (Tukker and Tischner, 2006)) is hindered by several challenges including the time dimension underpinning the integration of product and service, the system view spanning across organization boundaries, the assessment object (product, service, both, etc.), and the uncertainty associated with PSS performance (Settanni et al., 2014; Estrada et al., 2017). In the literature on (use and result oriented) PSS costing, most of the publications fall under one of the following categories; conceptualization and review papers, and papers introducing (quantitative or qualitative) costing models (Settanni et al., 2014; Medini et al., 2015; Medini and 
Boucher, 2016). In reference to the second stream, research works build on existing methods such as Life Cycle Costing (LCC), Activity Based Costing (ABC), and Game Theory, or extend the scope of existing approaches to bridge one or more of the PSS costing challenges (Settanni et al., 2014).

Although several authors underlined the need for a cross-organization perspective for assessing PSS economic value (relying on cost and revenue analysis), operational frameworks attempting to address such a need are still scarce. Further on, the time dimension is only partially addressed and the typical means for calculating costs relies on cost inference or retrospective models (i.e. derive statistically relationships between cost variables based on historical data) rather than attribution models (i.e. establish a causal link between cost variables prior to the cost estimate) (Datta and Roy, 2010; Settanni et al., 2014).

\section{A framework for systematic economic assessment of PSS configurations}

This section reports on an operational framework for assessing different value network configurations from an economical point view spanning over costs and revenues. The framework follows the general steps of the Through Life Costing (TLC) methodology (Settanni et al., 2014), uses Activity Based Costing (ABC) logic for calculating costs of product and service related activities, allocates the costs and revenues to the value network actors, and introduces an algorithmic approach to address PSS peculiarities during its operation. The methodological guidance underpinning the framework as well as the algorithmic approach for computing the indicators, are detailed in the following paragraphs. We follow TLC general steps to describe our framework, namely, functional unit identification, scope definition, knowledge elicitation and system visualization, and cost modelling and calculation.

Functional unit is seen as a quantified performance of the delivery system in fulfilling its identified function. Since the purpose of the current framework is to provide a systematic assessment without redefining the functional unit for each assessment project, the contracts are assumed to represent a comprehensive vision of the quantified performance. The contract is an agreement between two or more actors specifying obligations of parties to each other (Meier et al., 2010). Within a PSS, several contracts may occur : e.g. PSS contracts between a provider and customer, product and/or service purchasing contracts between PSS provider and suppliers.

Scope definition aims to define the boundaries of the assessment, that is, the actions performed and managed by people in organizations, the outcomes of the actions and the relationships between them (Settanni et al., 2014). Scope definition is derived from answering following questions : What PSS offerings ? What required activities for PSS provision? Who is involved in the PSS ?

Knowledge elicitation is based on collecting progressively and iteratively information about PSS during the (re)definition of a given offering. This process is supported by questionnaires and face-to-face meetings. Figure 1 shows a simplified overview of the cost elements that direct both the interviews and the visualisation. Visualisation consists in instantiating the concepts of Figure 1 depending on the 
context. The instantiation refers to describing a given case study concistently with those concepts. In this sense, the instances provide valuable insights for the subsequent cost modelling step.

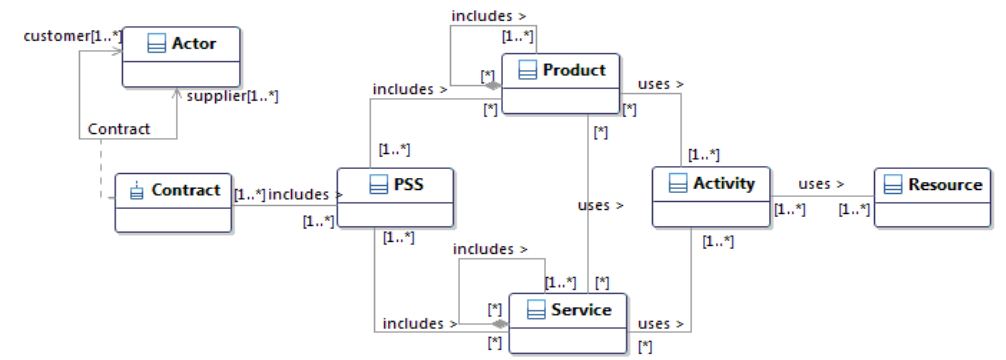

Fig. 1. Structure of cost elements

Cost and revenues modelling and calculation rely on one initial operation namely contract assignment and 4 main iterative and parallel operations as follows: contract management, contract services execution, contract material requirements calculation, and component replacement. Contract assignment is the initial calculation operation and it consists in assigning the available contracts (differentiated according to duration, PSS type, included services) to a demand profile specifying the number of required contracts by every single period throughout a given time horizon. Contract management, contract services execution, contract material requirement calculation, and component replacement are detailed in the following simplified 4 algorithms, which provide only a brief overview of main variables, procedures and functions (variables initialization is not presented).

Contract management is illustrated by Algorithm 1 which shows how contract status is updated according to current simulation period and to its starting date and duration; the way product are recovered upong contracts termination; and how the revenues are generated for the provider. While Algorithm 1 allows for updating current simulation period, Algorithms $2-4$ are executed for each simulation period and for each ongoing contract, and are triggered by Algorithm 1.

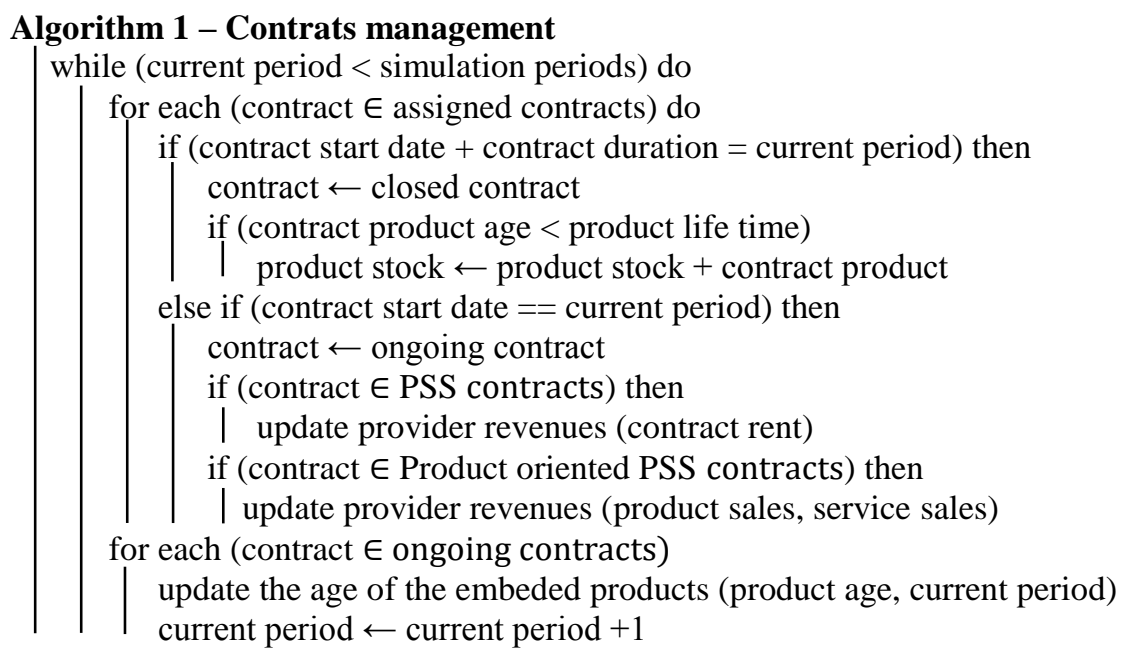


Contract service execution operation is reported on in Algorithm 2, which presents the way revenues and costs related to the service execution are taken into account and allocated to the service provider and customer.

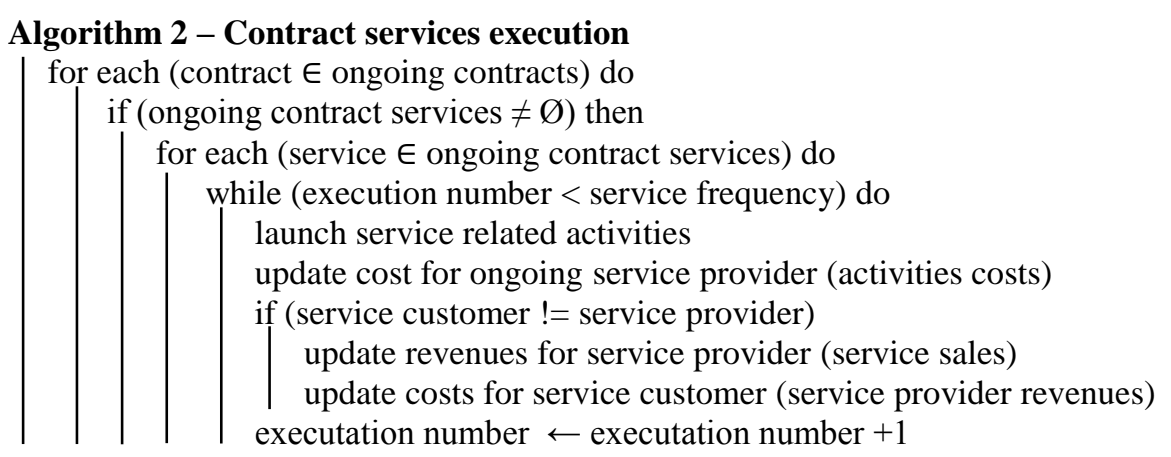

Contract material requirements calculation is illustrated by Algorithm 3 which shows how product provision is managed: the 'new' product is either taken from the stock or produced upon calculating the material requirements based on the PSS configuration (i.e. product quantity in the PSS), then the costs and revenues are generated for the product provider. Costs supported by the customer are updated based on the revenues of the provider.

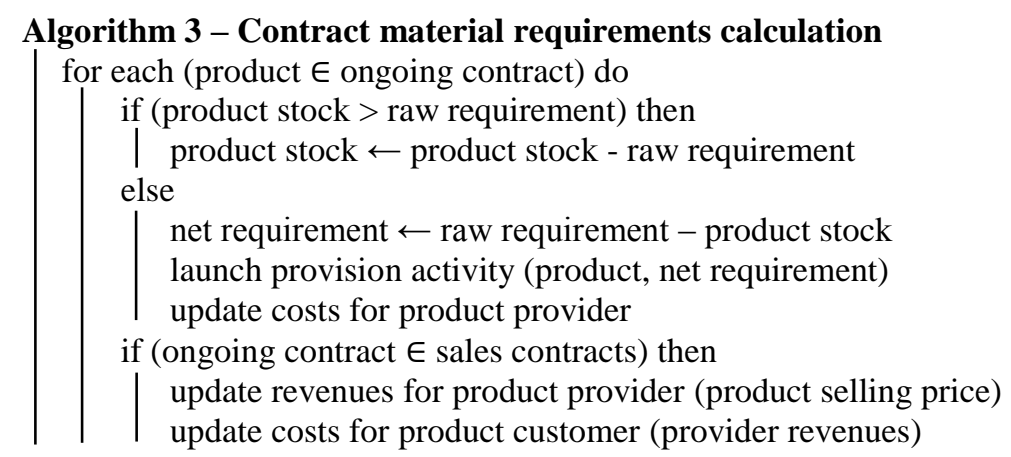

Component replacement process is described by Algorithm 4, where both component and product are referred to by product. First, the remaining lifetime of the product is calculated based on the product lifetime and age (updated following Algorithm 1). Then the number of required replacements is derived from the remaining lifetime and the duration of the simulation period. Replacement cost is then calculated based on the number of replacements and unit costs. The subsequent step consists in assigning the costs and revenues to the actors (service provider, product customer), depending on wether the replacement is ensured by a service or not.

Cost updates mentioned in the above algorithms follow a bottom up procedure flowing from activity costs identification up to cost assignment to the actors. First, activity costs are calculated based on resources' unit costs and quantities, if available, or using activity unit cost provided by domain experts (aggregate value considering the resources' unit costs and quantities). The contribution of a given activity to the cost of a given actor is derived from the unit activities' costs and the required volume 
of the product or service. The revenues are basically calculated based on the information provided in the contract, in particular contract rent, selling price in case of product oriented PSS, and service unit cost (cost for the customer).

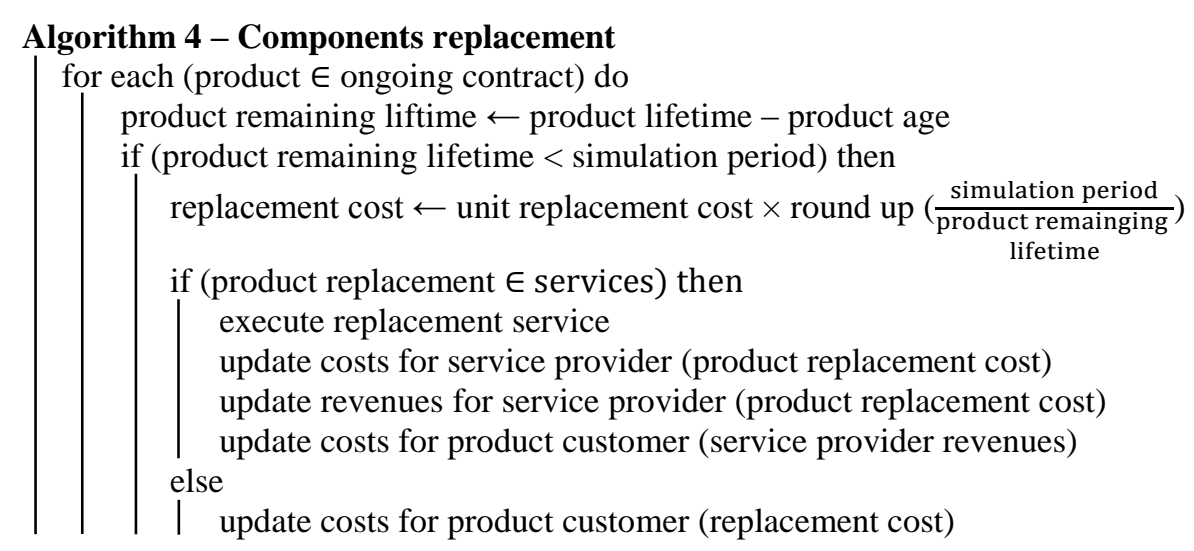

\section{$4 \quad$ Ilustrative example}

This section highlights briefly the operationality of the framework in terms of implementation and use. The framework is implemented into a software platform using the PHP language. In the following, we report on the use of the platform in the context of a PSS design project aiming to provide an industrial cleaning solution based on an autonomous cleaning robot and a set of services. The actors involved are a solution provider (A1), a battery system provider (A2), and a customer who is a big company in the meat transformation sector (A3). The case study was performed by the time only a prototype of the equipment is available. It is unit cost is estimated to around $100 \mathrm{k} €$. Around nine services have been identified as approapriate by the project consortium and have been included in the simulation. These services are classified into 4 main groups which are depicted in Table 1.

Table 1. Service groups and cost estimates

\begin{tabular}{lc}
\hline Service group & Cost estimates \\
\hline Customer co-design & $700 €$ \\
Installation services & $1200 €$ \\
Equipment cleaning & $400 €$ \\
Maintenance & $900 €$ \\
\hline
\end{tabular}

Figure 2 presents some of the results generated in two different PSS scenario with the same example. The two upper charts report on the evolution of cumulative costs and revenues of each actor in a use oriented PSS scenario. While the two others relate to a result oriented one. The results are shown for ten simulation periods, a period refers to one year. The demand has been generated randomly with values ranging from five to fifteen contracts a year, each of which is a 5 year contract.

A2 economic assessment is quite similar over the two situations as its main role consists in selling a battery systems to A1 regardless of the PSS type. In reference to 
A1, both the costs and revenues are higher in the result oriented scenario. However the revenues increase is more significant than the costs increase, and the subsequent net-profit is therefore higher. This is because in the result oriented scenario, A1 takes over the cleaning activity and thus generates revenues out of it, in addition to the equipment depreciation and maintenance services. For the customer (A3) only purchasing costs are calculated as this is sufficient for him to assess the offerings. A3 costs increased significantly between the two scenarios because in the use oriented scenario A3 ensures the cleaning process and bears its related costs, while in the result oriented scenario, he pays A1 for the full cleaning service. Thus, in order to evaluate the two scenarios from A3 viewpoint, cleaning costs in the first scenario should also be considered, that is to say, only the difference between cleaning costs supported by A3 in scenario 1 and scenario 2 is required to compare these sceanrios.

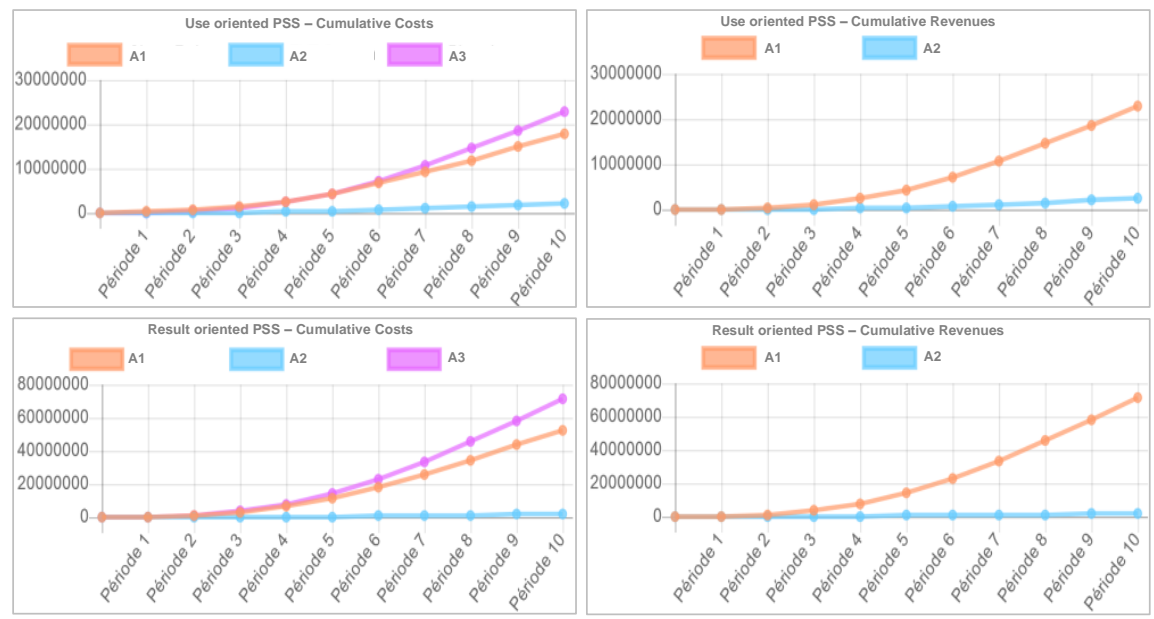

Fig. 2. An excerpt from the simulation results

\section{Conclusion}

The proposed framework extends existing research works (e.g. TLC, ABC) through enabling an attribution of the costs and revenues to the different actors involved in the PSS value network and considering the peculiarities of the use phase, especially product/component replacement and services included in the contract and which occur throughout the contract duration (e.g. maintenance).

Within the limit of the current paper, only an illustration of the applicability of the proposed approach has been provided. Further validation requires additional case studies with detailed data about the PSS in order to further discuss and anlyse the results. A sensitivity analysis would also be very useful for assessing the robustness of the results. More general improvements of the framework include taking into account uncertainty and non-monetary metrics such as environmental ones. 


\section{References}

1. Andriankaja A, Boucher, X., Medini, K.: Method to Design Integrated Product-Service Systems based on the Extended Functional Analysis Approach. CIRP Journal of Manufacturing Science and Technology 21, 120 - 139 (2018).

2. Baines, T.S., Lightfoot, H.W., Evans, S., Neely, A., Greenough, R., et al. State-of-the-art in product-service systems. Proceedings of the Institution of Mechanical Engineers, Part B: Journal of Engineering Manufacture 221(10), 1543 - 1552 (2007).

3. Baldassarre, B., Calabretta, G., Bocken, N.M.P., Jaskiewicz, T.: Bridging sustainable business model innovation and user-driven innovation: A process for sustainable value proposition design. Journal of Cleaner Production 147, 175-186 (2017).

4. Beuren, F. H., Ferreira, M.G., Gitirana, G., Miguel, P.C.: Product-service systems: a literature review on integrated products and services, Journal of Cleaner Production 47, 222-231 (2013).

5. Brehmer, M., Podoynitsyna, K., Langerak, F.: Sustainable business models as boundaryspanning systems of value transfers. Journal of Cleaner Production 172, 4514-4531(2018).

6. Cavalieri, S., Pezzotta, G.: Product-Service Systems Engineering: State of the art and research challenges. Computers in Industry 63, 278-288 (2012).

7. Datta, P., Roy, R.: Cost modelling techniques for availability type service support contracts: A literature review and empirical study. CIRP Journal of Manufacturing Science and Technology 3, 142-157 (2010).

8. Estrada, A., Romero, D., Pinto, R., Giuditta, P., Lagorio, A., Rondini, A.: A CostEngineering Method for Product-Service Systems Based on Stochastic Process Modelling: Bergamo's Bike-Sharing PSS. Procedia CIRP 64, 417-422 (2017).

9. Goedkoop, M., van Halen, C., te Rielen, H., Rommes, P.: Product service systems, ecological and economic basics. Report for Dutch Ministries of Environment (VROM) and Economic Affairs (EZ), The Hague (1999).

10. Medini K., Moreau V., Peillon S., Boucher X.: Transition to Product Service Systems: A Methodology Based on Scenarios Identification, Modelling and Evaluation. In : Luis M. Camarinha-Matos, L.M., Afsarmanesh, H. (eds.) PRO-VE: Working Conference on Virtual Enterprises, pp. 143 - 150. Springer, Heidelberg (2014).

11. Medini, K., Boucher, X., Peillon, S., Da Silva, C.M.: Product-Service Systems value chain configuration - a simulation based approach. Procedia CIRP, 30, 421-426 (2015).

12. Medini, K., Boucher, X.: Configuration of Product-Service Systems value networks Evidence from an innovative sector for sludge treatment. CIRP Journal of Manufacturing Science and Technology 12, 14-24 (2016).

13. Meier, H., Roy, R., Seliger, G.: Industrial Product-Service Systems. In IPS2. CIRP Annals Manufacturing Technology 59, 607-627 (2010).

14. Ramaswamy, V., Ozcan, K.: The Co-creation Paradigm. Stanford University Press, Stanford (2014).

15. Settanni, E., Newnes, L.B., Thenent, N.E., Parry, G., Goh, Y.M.: A through-life costing methodology for use in product-service-systems. International Journal of Production Economics 153, 161-177 (2014).

16. Smith, N., Wuest, T.: Identifying Key Aspects of Success for Product Service Systems. In: Lödding, H., Riedel, R., Thoben, K-D., von Cieminski, G., Kiritsis, D. (eds.) APMS 2017: Advances in Production Management Systems, pp. 231-238. Springer, Heidelberg (2017).

17. Tukker, A., Tischner, U.: Product-services as a research field: past, present and future. Reflections from a decade of research. Journal of Cleaner Production 14, 1552-1556 (2006). 